colours (Philos. Mag., Vol. XXIV, 1912) cannot be neglected by anyone interested in the subject, one of great theoretical and practical importance. He has recently published a paper (H. E. Ives and E. F. Kingsbury, Philos. Mag., Vol. XXXI, p. 290, 1916) continuing the earlier series, and dealing with the theory of the flicker photometer under unsymmetrical conditions. The same subject is dealt with from the more purely physiological point of view by C. E. Ferree and Gertrude Rand (Jl. of Exp. Psychol., Vol. I, p. 1, 1916), who describe a new method of heterochromatic photometry by the equality of brightness method, using the peripheral retina for eliminating the colour element.

Sir William Abney and W. Watson have published an important paper (Phil. Trans. R. S., Vol. CCXVI, A, p. 91, 1916) on the threshold of vision for different coloured lights.

Another case of violet or yellow-blue blindness, occurring in a healthy master of arts, aged 31 years, has been exhaustively examined by Sidney Abrutz ("Psyke" Meddelanden f. d. psykolog. Labor, Uppsala, Vol. I, pp. 2, 130, 1916). Helmbold (Arch. of Ophthal., Vol. XLV, p. 270, 1916) describes a matching test for the examination of colour vision, somewhat on the lines of Nagel's testcards.

R. A. Houston (Proc. R. S., Vol. CXII A, p. 424, 1916; Science Progress, 1917, p. 377) brings forward yet another theory of colour vision, based on the analogy of the selective action of the eye to the forced vibrations of a pendulum.

\title{
Antityphoid Inoculation and Ocular Lesions
}

Among the recently recorded sequelæ of antityphoid vaccination will be found a few examples of ocular lesions.* Although the number of reported cases is very limited, attention may well be drawn to them. It is important that all pathological phenomena arising in patients immediately or shortly after inoculation should be thoroughly investigated and that every endeavour should be made to determine if the relation between the vaccination and the subsequent lesions is causal or merely incidental. This question will doubtless be fully dealt with when the results of antityphoid inoculation in the Navy and Army during the last three years are published.

In a recent report to the Under-Secretary of State for Public Health in France, de Lapersonne, while recognizing the importance of the question under consideration, and the reliability of some of the observations, states that of the cases of ocular lesions following

\footnotetext{
*Morax.-Annal. d'Oculist., May and Nov., 1916.

Bond.-Canadian Med.Jl., 1915, p. 398.

de Lapersonne.-Arch.d'Ophtal.. March-April, 1917.
} 
antityphoid vaccination already noted in the French Army, the majority are devoid of scientific accuracy and cannot be seriously considered.

It is common knowledge that owing to imperfect asepsis, severe septic infections may follow the administration of antityphoid vaccine. de Lapersonne quotes the case of a soldier who after a second or third injection suffered from multiple boils, septic pneumonia, and metastatic purulent uveitis leading to the loss of one eye. Such complications cannot be attributed to the vaccine per se, and moreover are wholly preventable.

Observations of sequelæ occurring in other organs lend support to the view held by this observer that the severe reaction which follows antityphoid inoculation in some patients may excite inflammation in an eye which has previously been the subject of keratitis, iridocyclitis, etc., and he considers that there is a certain analogy between such an occurrence and the ocular lesions which occasionally follow injections of tuberculin, or the administration of arsenical preparations in syphilitic patients.

In one of the cases published by Morax (loc. cit.) the herpes occurred, after the fourth injection, in an eye with scars of a former keratitis; in the other, the corneal lesion appeared after the third injection, but there is no evidence that the eye had had any previous trouble. In both patients the reaction after the injection was noted as intense.

In the observations published by Bond, two cases are mentioned in which the administration of vaccine seemed to excite trouble in tissues which had previously been the seat of disease : (1) a sergeant who had had rheumatism in one knee in August was inoculated in October; the inoculation was followed by severe pain in the previously inflamed knee-joint; (2) an officer in whom inoculation was followed, on each of two occasions, by conjunctivitis in an eye which had previously been the seat of inflammation.

\section{Retinal Hæmorrhage}

As having a bearing on a subject which has recently received a good deal of attention in ophthalmic literature we transcribe from the Lancet of April 14, 1917, the following synopsis of an article by Amsler (Correspondenz-Blatt f. Schweizer Aerzte, 1917, p. 318) dealing with 164 cases of retinal hæmorrhage in private and hospital practice. "Stated in percentages, the etiological factors were as follows; arterio-sclerosis, 55 ; heart disease, 8 ; albuminuria, $8 ;$ glycosuria, $3 ;$ menopause, 6 . The percentage incidence in successive decades from 20 to 70 years was $4,7,13,27$, and 36 respectively, and 13 above seventy years. Nearly two-thirds of the cases were in women, and in them the prognosis was relatively more 